\title{
Utilization of Social Media in Higher Education with a Reflection on Turkey
}

\author{
Tuna Hacaloglu ${ }^{1}$, Cigdem Turhan ${ }^{2}$ and Ibrahim Akman $^{3}$
}

\begin{abstract}
Social media has become an important part of today's lifestyle changing the way people communicate, entertain, share information, etc. In the past few years, education has become another area where social media has shown an impact. The incorporation of social media in higher education courses enhances the interaction and collaboration between students and faculty, increasing the students' participation, involvement and motivation in the learning process. There have been many examples of blended learning environments where social media is integrated into a course curriculum. The aim of this study is to provide an overview of various examples which successfully integrated social media into the higher education classrooms to provide insight and feedback to researchers and faculty members for future practices. In addition, considering the high interest in using social media in Turkey among the young population, the study focuses on presenting the current utilization of social media in Turkish higher education institutions.
\end{abstract}

Keywords—social media, higher education, learning

\section{INTRODUCTION}

$\mathrm{W}$ ITH the widespread adoption of social media in the past few decades, the way people interact, communicate, collaborate, share information and entertain has changed drastically. Social networks cater a variety of interests such as blogging, forums, chats, photograph/video sharing, etc. to users of all ages, from different education backgrounds anywhere in the world. According to [1], there are 2.8 billion active social media users in the world which has increased by $22 \%$ since 2016. This significant interest has motivated researchers and academicians in incorporating social media to higher education. When we focus on Turkey, the majority of population shows a great interest in social media with 48 million active social media accounts as of January, 20171 . In spite of this wide interest, the incorporation of social media in higher education institutions is still in the infancy stage and the literature has not matured in this respect. This situation has motivated the authors to review the current state of social media usage for education in universities both in the world and specifically in Turkey. This will hopefully shed light for the

Tuna Hacaloglu ${ }^{1}$ Department of Information Systems Engineering, Atilim University.

Cigdem Turhan ${ }^{2}$, Department of Software Engineering, Atilim University. Ibrahim $\mathrm{Akman}^{3}$ Department of Computer Engineering, Atilim University. direction of future research.

In this context, this paper aims to present an overview of the studies in the past decade that have utilized social media in university education. Hopefully, this short review will provide insight and feedback to academicians and researchers who would like to benefit from social media for academic purposes.

The paper is organized as follows. The introduction is followed by the literature review on the social media usage in higher education both in the world and in Turkey ending with the conclusion.

\section{SOCIAL MEDIA USAGE IN HighER EdUCATION}

Social media offers users the opportunities of learning based on their own individual preferences and area of interests and encourages continuous learning [2]. According to [3], social learning has considerable contributions to the Education and Training Principles defined by the European Union. These principles are presented as encouraging innovation and creativity, increasing quality and effectiveness of learning opportunities and results, life-long learning, realization of mobile learning, supporting the equality and active citizenship principles. Since social media is part of young people's lifestyle already, integrating the technology into the learning process will be a natural step forward, consequently, enabling the learning process to be a part of their life. According to recent studies, social media sites such as Facebook, Twitter, YouTube, blogs, and wikis are being used increasingly in education to disseminate information, communicate and interact with students.

In a study on the effect of social networks on learning conducted by Pearson Learning Group in 2013 [4], it is concluded that in 8000 universities, $41 \%$ of the academics are using social media actively for educational purposes and this rate shows an important increase from 34\% in 2012.

Being the oldest and most popular application of social media, Facebook has been used widely as the platform for social media in education. According to a survey by 'Education, Technology Charity Jisc' [5], more than a quarter of university students use a form of social media to contact their instructors where the most commonly used social media channel is Facebook with a rate of $85 \%$. Accordingly, in [6] the authors posit that social media is increasingly being used in higher education to improve teaching, providing an active atmosphere for learning.

According to a research in [7], Facebook groups were used 
in 12 courses between 2012 and 2014 covering the following aspects:

1) Creation of a timeline or Facebook Group for a curriculum course

2) Creation of an environment and platform for homework and revision materials

3) Conducting subject specific discussions

4) Peer teaching and support

5) Providing a research tool to share ideas, video and resources

Furthermore, [8] proposed that Facebook was the ideal platform for a blended learning environment. In the study, among the 120 architecture students who were enrolled in a first-year elective course, a majority of the students felt that the incorporation of Facebook in the classwork helped them to develop peer relationships. In another application of social media in a university course, [9] utilized Facebook in their software design project to connect students from two different universities for establishing collaboration on a project. In this study, students preferred Facebook over other platforms such as Skype, wikis, e-mail and instant messaging to communicate.

In addition, medical students formed a group named "Medical Mnemonics" to share study aids on bone names, disease symptoms, etc. [10]. Also in the study [11], the authors compare the utilization of Twitter, Facebook and Youtube in an introductory statistics course and provide recommendations for instructors in using different social media tools for their lectures such as giving an assignment to create a short YouTube video to present a topic in the course. Also, the authors set up a Facebook group for students to provide opportunities to ask questions about course material and get assistance.

In the study [12], it is stated that social media increases the interaction level in distance-learning classes in three ways: student-student, student-teacher, and student-content. In this context, in the study [13] it is stated that social media tools such as Google Docs and SurveyMonkey facilitate the interaction and provide a control over the content. Moreover, with Google Docs, students can participate in the discussions anonymously and ask questions to their teachers.

Furthermore, [14] developed a social media tool called Edooware to be used in university education, and measured the social learning perception of students by using the Social Media Acceptance Model. They have observed that the students were more motivated to use the Edooware tool and concluded that the tool proves the importance of enjoyment, social influence and functionality features which are usually not included in conventional learning platforms.

As shown in the previous examples, various studies investigate the effects of using social media in higher education and proves its contribution to learning. Yet, in Turkey whose young population extensively uses social networks, such applications in university education are only a few according to the literature review. The existing research is limited only to investigating the future benefits of using social media in the classroom.

Some of the recent studies conducted in Turkey are as follows. In their study, [15] provide social media support to 60 students in their courses for a semester and evaluate the student opinions about social media enhanced education. The results show that social media has a positive effect on the student learning process and improves the educational activities. In another study [16], the authors suggest a theoretical model to investigate how collaborative learning is affected by social media. With this aim, they have conducted a survey in one of the largest universities in Turkey. Their findings show that social media contributes to peer interaction as well as to interaction between students and faculty and also improves course engagement. In another study that has been conducted in Turkey [17], a survey was distributed to 102 university students from various departments. They conclude that generally, the students are positively affected by the utilization of social media. However, the study also emphasizes that the negative usage of social media can restrict the cognitive development of students.

Facebook being one the earliest and most popular social media tool in Turkey, has become the focus point of several research in this context. Consequently, there have been various studies specifically addressing the integration of Facebook in learning. The reason behind this choice can be based on the research [18] which claims that it is easy and cheap to integrate social media such as Facebook with minimum effort to the education processes. The authors in [19] have investigated the incorporation of Facebook into a course in the Biology Education department with 30 senior students. A Facebook group was used as a platform to publish lecture notes, announcements, videos, animations, links and homeworks. The result of the study indicate that Facebook usage strengthens the communication between students and faculty as well as increasing information sharing and collaboration. In addition, visualizing the course contents has increased the students' interest in the course. In addition, [20] present the results of a study with 67 faculty members with various degrees and conclude that Facebook contributes to social interaction among students and similarly increases teacher-student communication.

As seen by the literature review in Turkey, most of the studies deal with investigating the student attitude towards social media enhanced learning, and there are only a few studies which focus on how to integrate social media into the course curriculum. These studies mostly describe a one-way content sharing such as publishing course-related materials which is similar to using an LMS system, not utilizing the full capabilities of social media for multi-way interaction and collaboration.

\section{CONCLUSION}

In this study, an overview of the existing studies of social media usage in higher education have been presented in the world, and more specifically in Turkey. The utilization of 
social networks in higher education has positive impact especially in establishing interaction, communication and collaboration between students and faculty, and increases the motivation and involvement of students in their courses. In contrast, one of the studies point out the negative effects of social media in education if it is not used appropriately.

According to the literature survey, it is concluded that there is a lack of studies investigating the usage of social media in Turkish universities. Hopefully this study will provide insight and feedback to faculty and researchers who are interested in incorporating social media tools to their courses. In conclusion, usage of social media in education can result in more effective and attractive learning opportunities and provide a more agreeable teaching infrastructure both for students and faculty.

\section{REFERENCES}

[1] A. Hutchinson, (2017). Top social network demographics 2017. Available: http://www.socialmediatoday.com/social-networks/topsocial-network-demographics-2017-infographic.

[2] G. Bull, A. Thompson, M. Searson, J. Garofalo, J. Park, C. Young, and J. Lee, "Connecting informal and formal learning experiences in the age of participatory media," Contemporary Issues in Technology and Teacher Education, vol.8, no.2, pp. 100-107, 2008.

[3] C. Redecker, K. Ala-Mutka, and Y. Punie, Y, Learning 2.0 - The Impact of Social Media on Learning in Europe: Policy Brief, JRC Technical Notes, 2010.

[4] D. Arslan, (2013). Egitim Sınıflardan Sosyal Ağlara Kayıyor. Available: http://sosyalmedya.co/egitim-siniflardansosyal-aglara-kayiyorarastirma/.

[5] C. Parr, (2015). One in four students uses social media to contact university staff. Times Higher Education, Available: https://www.timeshighereducation.com/news/one-in-four-students-usessocial-media-to-contact-university-staff/2018798.article.

[6] P.A. Tess, "The role of social media in higher education classes (real and virtual) - A literature review," Computers in Human Behavior, vol. 29, pp. A60-A68, 2013. https://doi.org/10.1016/j.chb.2012.12.032

[7] E. Miron and G. Ravid, "Facebook groups as an academic teaching aid: Case Study and recommendations for educators," Journal of Educational Technology and Society, vol. 18, no. 4, pp. 371-384, 2015.

[8] J. McCarthy, J. "Blended Learning environments: Using social networking sites to enhance the first year experience," Australasian Journal of Educational Technology, vol. 26, no. 6, pp. 729-740, 2010. https://doi.org/10.14742/ajet.1039

[9] T. Charlton, M. Devlin, and S. Drummond, "Using Facebook to improve communication in undergraduate software development teams," Computer Science Education, vol. 19, pp. 273-292, 2009. https://doi.org/10.1080/08993400903384935

[10] T. Green and B. Bailey, "Academic uses of Facebook: Endless possibilities or endless peril?” TechTrends, vol. 54, pp. 20-22, 2010. https://doi.org/10.1007/s11528-010-0398-Z

[11] M.Everson, E. Gundlach, and J. Miller, "Social media and the introductory statistics course," Computers in Human Behavior, vol. 29, pp. A69-A81, 2013.

https://doi.org/10.1016/j.chb.2012.12.033

[12] S. Brownson, "Embedding social media tools in online learning courses," Journal of Research in Innovative Teaching, vol. 7, no. 1, pp. 112-118, 2014.

[13] D.R.George, T.D. Dreibelbis, and B. Aumiller, "How we used two social media tools to enhance aspects of active learning during lectures," Medical Teacher, vol. 35, pp. 985-988, 2013. https://doi.org/10.3109/0142159X.2013.818631

[14] V. Balakrishnan, T.K. Liew, S. Pourgholaminejad, "Fun learning with Edooware - A social media enabled tool," Computers \& Education, vol. 80, pp. 39-47, 2015.

https://doi.org/10.1016/j.compedu.2014.08.008
[15] A. Toğay, T.E. Akdur, İ.C. Yetişken, A. Bilici, (2013). Eğitim süreçlerinde sosyal ağların kullanımı: Bir MYO deneyimi, Available. http://ab.org.tr/ab13/bildiri/302.pdf

[16] A. Bozanta and S. Mardikyan, "The effects of social media use on collaborative learning: A case of Turkey," Turkish Online Journal of Distance Education, vol.18, no.1, Article 7, pp.96-110, 2017.

[17] U. Köse, "Effects of social media on students: An evaluation approach in Turkey," In: Issa, T., Isaias, P., Kommers, P. (eds.) Social Networking and Education. Lecture Notes in Social Networks, Springer, Cham., 2016. https://doi.org/10.1007/978-3-319-17716-8_12

[18] Y. Gulbahar, F. Kalelioglu, O. Madran, "Sosyal agların egitim amaçlı kullanımı" presented at XV.Türkiye'de Internet kullanımı konferansı, Istanbul, Istanbul Teknik Üniversitesi, 2010.

[19] İ.Ü. Yapıc1, and M. Hevedanl, M, "Educational use of social networks: Facebook case study," European Journal of Research on Education, Special Issue: Educational Technology and Lifelong Learning, pp. 1621, 2014.

[20] F. Tiryakioglu, F. Erzurum, "Use of Social Networks as an Education Tool," Contemporary Educational Technology, vol. 2, no. 2, pp. 135$150,2011$. 